\title{
A CASE OF TENSION PNEUMOPERITONEUM DUE TO COLONIC BAROTRAUMA WITH COMPRESSED AIR
}

Shashidhara $\mathrm{P}^{1}$, Shaziya Hassan $\mathrm{Ali}^{2}$, Seshasayi $\mathrm{M}^{3}$

\section{HOW TO CITE THIS ARTICLE:}

Shashidhara P, Shaziya Hassan Ali, Seshasayi M. "A Case of Tension Pneumoperitoneum Due to Colonic Barotrauma with Compressed Air". Journal of Evolution of Medical and Dental Sciences 2014; Vol. 3, Issue 48, September 29; Page: 11644-11647, DOI: 10.14260/jemds/2014/3529

CASE REPORT: A 23 year old male working in a biscuit factory was brought to emergency department by the coworkers at 4PM with pain abdomen and distension and bleeding per rectum. On further questioning the patient confessed that his co-workers had held him firmly and directed the stream of air from a compressed-air pipeline towards his anal region in the morning.

On examination, he was alerting conscious and oriented and tachypneic. The respiratory rate was $30 / \mathrm{min}, \mathrm{SPO}_{2}-80 \%$, Pulse was $120 / \mathrm{min}$ and B.P. 120/80 mm Hg. On palpation, Abdomen was grossly distended (Fig. 1), tense with generalized tenderness and rigidity of abdominal wall. The percussion note was tympanitic and liver dullness obliterated. No free fluid was detected. Bowel sounds were absent. Examination of the perineum did not show any external injury. Rectal examination showed faeces mixed with fresh blood but did not reveal any laceration or perforation in the anal canal or rectum. Straight X-ray abdomen in erect position showed extensive pneumoperitoneum (Fig. 2)

Abdominal decompression was made in view of tension pneumoperitoneum, low saturation and tachypnea. A 20G needle was inserted in the right upper quadrant just lateral to rectus abdominis muscle following which the pneumoperitoneum reduced with sudden improvement in the oxygen saturation (98\%) and tachypnea got reduced. A clinical diagnosis of pneumatic rupture of hollow viscera, probably colon was made.

An emergency exploratory laparotomy under general anesthesia through a mid-midline incision was carried out. Intraoperative, a single perforation of $3 \times 2 \mathrm{cms}$ in the ant mesenteric border of transverse colon $15 \mathrm{cms}$ away from the hepatic flexure (Fig. 3) with fecal spillage into the peritoneal cavity was noted. There was also sero muscular tear along the entire length of the transverse colon (Fig. 4) and extensive contusions around the entire colon.

Thorough visceral inspection of abdomen did not reveal any other visceral injury. The perforation was closed in two layers using 2-0 vicryl and 2-0 silk and the areas of serosal tears were sutured using 2-0 silk. After a thorough peritoneal lavage, a de functioning transverse loop colostomy was placed in the right upper quadrant and the wound was closed in layers with an abdominal drain. Postoperative recovery was quite uneventful and colostomy reversal is planned later.

DISCUSSION: Compressed air injuries should be taken seriously because the high pressure of compressed air directed to rectum can overcome barriers as clothes and anal sphincter delivering enormous amount of pressurized air into the rectum, resulting in rectal and colonic perforation and development of tension pneumoperitoneum.

Pneumatic colonic injury has been reported sporadically since the first report by Stone in 1904(2) and reviewed in detail by Brown and Dwinelle (3) in 1942. An experimental study on the relationship between intestinal rupture and air pressure was performed by Burt (4) in 1931. 
According to this study of the four layers of the intestinal wall, the mucosa is the strongest layer and when pressure increases progressively the muscle and serosa tear first, then the mucosa. A pressure of 3.99 psi tears the muscle and serosal layer of intestine and 4.07psi can rupture the whole intestinal wall leading to perforation.

The usual pressure of air coming out of an air compressor is $50-150$ psi which is $10-30$ times greater than the pressure needed for intestinal perforation. According to Laplace's law, wall tension is directly proportional to the intramural pressure and colon diameter. Therefore colonoscopy barotrauma injuries occurring most commonly in the cecum as a result of its largest diameter.(5)

Kozarek and Sanowski showed that the cecum perforation occur at lower pressures (mean, $120 \mathrm{~mm} \mathrm{Hg}$ ) compared to the sigmoid colon (mean, $202 \mathrm{~mm} \mathrm{Hg}$ ) on the cadaver by colonoscopy.(6) Reported colon injuries caused by the air compressor in the literature are in different regions but mostly in the recto sigmoid junction. ${ }^{(7,8)}$ This situation is contrary to the law of Laplace.

This is because the recto sigmoid junction sensitizes with the high air pressure and so perforation in this area will reduce the air passing through proximal of the colon or decrease in the pressure. The rectosigmoid junction is the first part of colon that cannot stand higher pressure while anus, distal rectum are supported with pelvic structures. Intraluminal pressure is not the only reason of intestinal injury, but a sudden and high flow velocity of air at the same time is important.(7.8) In our case full-thickness perforation of transverse colon was found.

In the case of delay in diagnosis of a colonic perforation caused by barotrauma colostomy is recommended. However, in young patients without any signs of peritonitis, primary repair or resection anastomosis may be preferred if no delay in diagnosis.(8) In our case colostomy was done proximal to perforation in the right upper quadrant in view of fecal peritonitis and delayed presentation of the patient to hospital.

Some patients may withhold information, trying to protect the guilty party or due to embarrassment. In such cases, the general symptoms are abdominal pain, abdominal distension, rectorrhagia, tachypnea, and tachycardia. Tension pneumoperitoneum is a characteristic presentation. $(1,9,10)$ Death can occur due to acute air embolism, acute fat embolism, acute respiratory insufficiency due to enhanced intra-abdominal pressure and chest compression, acute heart failure due to insufficient preload and peritoneal shock. ${ }^{(9)}$

Percutaneous decompression of the tension pneumoperitoneum can be accomplished by inserting a cannula or a Veress needle into the abdomen.(11) 16-gauge angiocath was inserted per cutaneously in the right upper quadrant of the abdomen for decompression with alleviation of respiratory and hemodynamic problems.(12) The overall mortality of pneumatic rupture of the bowel was $65 \%$. If the acute shock was not immediately fatal, the survival depends on further treatment. Surgery reduced mortality to $42 \%{ }^{(13)}$.

CONCLUSION: Colonic injuries occur with a high pressure air compressor are reported especially in the industrial zones. If a patient who works in this segment presents with abdominal distension and pain, perforation of colon by barotrauma should be considered in the differential diagnosis of peritonitis. Though it has high morbidity and mortality rates, surgery reduces the mortality, so decision for surgery must be made as quickly as possible time is the essential factor. 


\section{REFERENCES:}

1. Zunzunegui RG, Werner AM, Gamblin TC, Stephens JL, Ashley DW. Colorectal blowout from compressed air: case report. J Trauma. 2002; 52 (4): 793-795.doi pubmed.

2. Stone GW rupture o bowel caused by compressed air. Lancet 1904; 2: 216.

3. Brown RK, Dwinelle JH. Rupture of the colon by compressed air. Ann. Surg. 1942; 115: 13-20.

4. Burt CAV Pneumatic rupture of the intestinal canal with experimental data showing the mechanism of perforation and the pressure required Arch Surg. 1931; 22: 875-902.

5. Woltjen JA, "A retrospective analysis of cecal barotrauma caused by colonoscopy air flow and pressure," in Gastrointest Endosc, 2005; 61:37-45.

6. Kozarek RA, Sanowski RA, "Use of pressure release valve to prevent colonic injury during colonoscopy,"in Gastrointest Endosc, 1980; 26: 139-142.

7. Jin Yi Choi, et al, "Colon Barotrauma Caused by Compressed Air," in Intest Res, 2013; 11(3): 213-216,

8. Suh HH, Kim YJ, Kim SK, "Colorectal injury by compressed air-a report of 2 cases," in J Korean Med Sci, 1996; 11: 179-182.

9. Weber M, Kolbus F, Dressler J, Lessig R. Survived ileocecal blowout from compressed air. Int J Legal Med. 2011; 125 (2): 283-287.

10. Avallone S, La Torre M, Meurette G. Rectal injury by compressed air. J Trauma. 2010; 68 (1): 248.

11. Millar DM. Tension pneumoperitoneum: a simple solution. Br J Hosp Med. 1988; 40 (2): 149.

12. Chan SY, Kirsch CM, Jensen WA, Sherck J. Tension pneumoperitoneum. West J Med. 1996; 165 (1-2): 61-64.

13. Brown RK, Dwinelle JH. Rupture of the Colon by Compressed Air: Report of Three Cases. Ann Surg. 1942; 115 (1): 13-20.

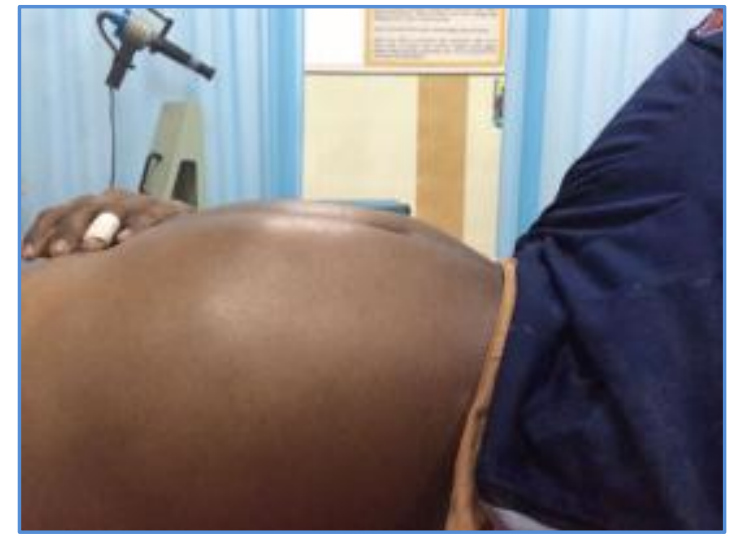

Fig. 1: showing abdominal distension of our patient at the time of admission

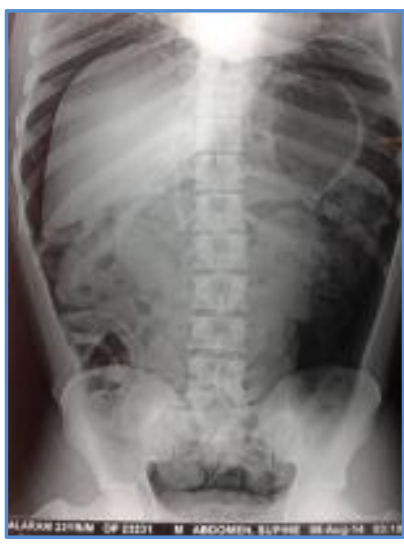

Fig. 2: X-ray erect abdomen picture of our patient showing extensive pneumoperitoneum 


\section{CASE REPORT}

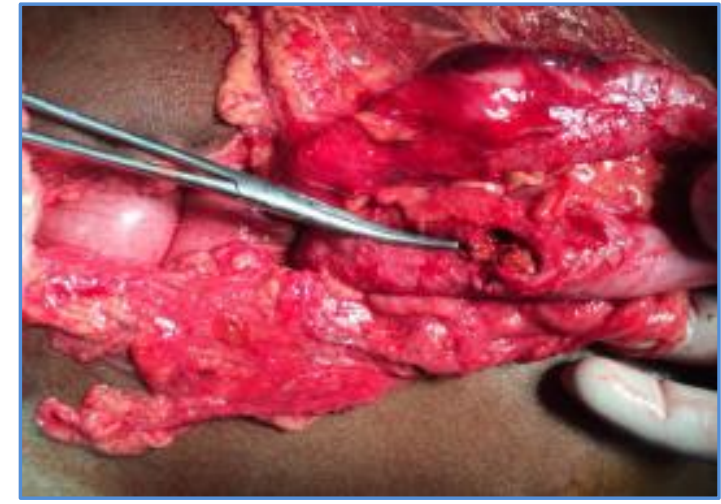

Fig. 3: intra operative picture showing perforation in the transverse colon with fecal contamination

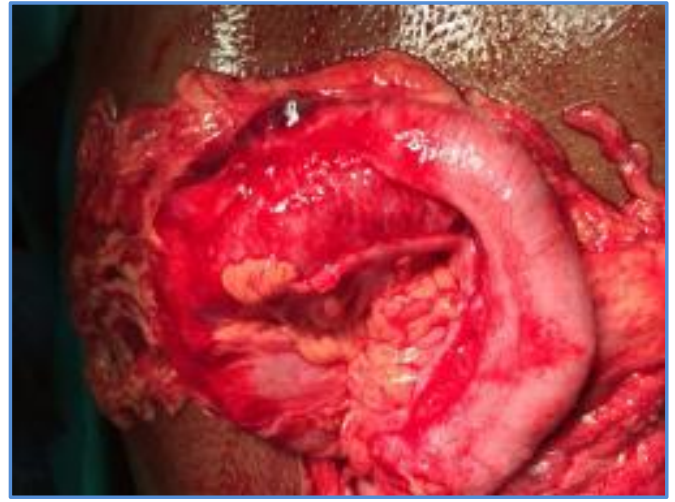

Fig. 4: intra operative picture showing extensive splaying of the sero muscular layer and contusion in the transverse colon

\section{AUTHORS:}

1. Shashidhara P.

2. Shaziya Hassan Ali

3. Seshasayi M.

\section{PARTICULARS OF CONTRIBUTORS:}

1. Assistant Professor, Department of Surgery, RRMCH, Bangalore.

2. Post Graduate, Department of Surgery, RRMCH, Bangalore.

3. Professor, Department of Surgery, RRMCH, Bangalore.

\section{NAME ADDRESS EMAIL ID OF THE CORRESPONDING AUTHOR:}

Dr. Shashidhara $\mathrm{P}$, \# 33/1, 1st 'B' Cross,

$5^{\text {th }}$ Block, Banashankari $3^{\text {rd }}$ Stage,

Bangalore-560085.

Email: dr.shashi85@gmail.com

Date of Submission: 12/09/2014.

Date of Peer Review: 13/09/2014.

Date of Acceptance: 19/09/2014.

Date of Publishing: 29/09/2014. 